\title{
Expression of Raptor and Rictor and their relationships with angiogenesis in colorectal cancer
}

\author{
F. F. WEN", X. Y. LI", Y. Y. LI, S. HE, X. Y. XU, Y. H. LIU, L. LIU, S. H. WU* \\ Department of Pathology, Binzhou Medical University Hospital, Binzhou, Shandong, China \\ *Correspondence: wsh6108@126.com \\ "Contributed equally to this work.
}

Received July 5, 2019 / Accepted September 4, 2019

\begin{abstract}
Mammalian target of rapamycin (mTOR) has two subtypes, i.e., mTORC1 and mTORC2, which contain the Raptor and Rictor core molecules, respectively. The effect of Raptor and Rictor on hypoxia inducible factor (HIF)-1 $\alpha$, HIF-2 $\alpha$, and vascular endothelial growth factor (VEGF) in colorectal cancer (CRC) is unclear. In this work, we investigated the correlations among Raptor, Rictor, HIF-1 $\alpha$, HIF-2 $\alpha$, and VEGF expression in CRC. We subsequently analyzed the clinicopathological features of patients. Immunohistochemistry, western blot, and RT-PCR analyses were performed to detect the expression of Raptor, Rictor, HIF-1 $\alpha$, HIF-2 $\alpha$, and VEGF in 120 cases of CRC and 60 cases of normal colorectal mucosa. CD34 was used to label microvascular density (MVD), which was found to be higher in patients with positive Raptor or Rictor than in those with negative Raptor or Rictor. The positive rates of Raptor, Rictor, HIF-1 $\alpha$, HIF-2 $\alpha$, and VEGF in CRC were significantly higher than in normal colorectal mucosa. Raptor expression was positively correlated with HIF-1 $\alpha$ and VEGF but not with HIF-2 $\alpha$ expression. By contrast, Rictor expression was positively correlated with HIF-2 $\alpha$ and VEGF but not with HIF-1 $\alpha$ expression. Survival analysis further indicated that Raptor, Rictor, HIF-1 $\alpha$, HIF-2 $\alpha$, VEGF and lymph node metastasis were independent prognostic factors in CRC. To conclude, Raptor and Rictor expression was related to the initiation and development of CRC and angiogenesis in different ways. The combined detection of Raptor and Rictor is important for patients with colorectal carcinoma in prognosis and optimal therapy.
\end{abstract}

Key words: colorectal cancer, tumor angiogenesis, Raptor, Rictor, prognosis

Angiogenesis is the basis for the survival of tumors. Since the American scholar Folkman proposed the theory of tumor-growth-dependent blood vessels in the 1970s, the correlation between tumor growth, metastasis and angiogenesis has attracted great attention [1-2]. Therefore, drugs targeting tumor angiogenesis, such as bevacizumab, sunitinib, and sorafenib, came into being [3-5]. However, a large number of clinical studies show that the efficacy of anti-angiogenesis drugs is not expected in preclinical studies, often due to drug resistance leading to treatment failure [6]. Therefore, the mechanisms and targets of tumor angiogenesis need to be explored.

The mechanism of tumor angiogenesis is a complex and multi-step process that begins with the imbalance between angiogenic factors and anti-angiogenic factors. In addition, many cellular signaling pathways are involved in regulating tumor angiogenesis $[7,8]$. Recent studies have shown that the mammalian target of rapamycin (mTOR) is a key molecule in the PI3K/AKT/mTOR signaling pathways and plays an important role in regulating cell proliferation, apoptosis, migration, and tumor blood vessels [9].

The development of colorectal cancer (CRC) occurs through two stages, i.e., bloodlessness and vascularization. In the absence of blood vessels, CRC cells disperse to the neighboring vascular system. During this time, the tumor growth is slow and the apoptosis rate is high. The tumor volume is generally not more than $2-3 \mathrm{~mm}^{3}$. However, the tumor increases rapidly and can metastasize in the vascular stage. Therefore, angiogenesis can directly affect the growth, invasion and metastasis of CRC. Thus, the key factors of tumor angiogenesis and its regulatory mechanisms have become one of the areas of interest in the study of tumor targeted therapy. Miyazawa's [10] study has shown that the $\mathrm{PI} 3 \mathrm{~K} / \mathrm{AKT} / \mathrm{mTOR}$ signaling pathways are closely related to tumor angiogenesis. The treatment effect of mTOR blockers such as rapamycin and strychnine is not satisfactory. In this study, we detected the expression levels of mTOR core molecules Raptor and Rictor, hypoxia inducible factor (HIF)- 
$1 \alpha$, HIF-2 $\alpha$ and vascular endothelial growth factor (VEGF) and analyzed the correlation between them and microvascular density (MVD) in CRC. The study of the relationship between Raptor, Rictor and angiogenesis and its significance in CRC aimed to further clarify the mechanism of angiogenesis and provide a new foundation for treatment.

\section{Materials and methods}

Clinical specimens and patients' data. A total of 120 CRC tissue samples at different stages were collected from the Department of Pathology of Binzhou Medical University Hospital from January 2013 to June 2015. Samples included early and advanced CRC. Parts of the tissue samples were immediately frozen in liquid nitrogen and were routinely fixed in $10 \%$ neutral buffered formalin. Cancer tissues were cut into wedge shapes, whereas normal tissues were cut at least $5 \mathrm{~cm}$ away from the tumor margin. All CRC patients were clinically and pathologically proven to have not received preoperative chemotherapy or radiotherapy before the operation. All specimens were collected with the informed consent of the patients, and the Ethics Committee of Binzhou Medical University Hospital approved the protocols used in this study. The clinicopathological classification was performed according to the National Comprehensive Cancer Network classification parameters [11]. Demographic and clinicopathological parameters were prospectively recorded using a chart review.

Immunohistochemistry. EnVision staining was used. Before staining, paraffin-embedded tissue blocks were cut in $4 \mu \mathrm{m}$ thickness. The sections were deparaffinized in an oven at $60^{\circ} \mathrm{C}$ for $60 \mathrm{~min}$ and then rehydrated with two and three changes of xylene and ethanol, respectively. Antigen retrieval was performed using the high-pressure hot retrieval method. Endogenous peroxidase activity was quenched by incubation with $3 \%$ hydrogen peroxide for 10 min at room temperature. Nonspecific binding was blocked by incubating sections with $10 \%$ normal goat serum in PBS for $30 \mathrm{~min}$ at room temperature. Without washing, sections were incubated with rabbit monoclonal antibody against human mammalian target of Raptor (1:100; Abcam, ab40768), Rictor (1:100; Abcam, ab104838), HIF-1a (1:100; Abcam, ab51608), HIF-2a (1:100; Abcam, ab199), and VEGF (1:100; Abcam, ab1316) at $4^{\circ} \mathrm{C}$ overnight. The sections were then incubated with horseradish peroxidase-conjugated secondary goat anti-rabbit antibody (Abcam, San Francisco, USA) for $60 \mathrm{~min}$ at room temperature. The sections were washed with PBS and treated with Metal-Enhanced DAB Substrate Kit (Thermo Scientific, Waltham, USA) to visualize the antigen-antibody complex. Two researchers who were unaware of the clinicopathological status of the specimens scored each section separately. The percentage of stained cells on each section was scored as follows: $0(<5 \%)$, 1 (5-25\%), 2 (26-50\%), and 3 (>50\%). Staining intensity was scored as follows: 0 (no staining), 1 (weak staining),
2 (moderate staining), and 3 (strong staining). The final score of each specimen was calculated by multiplying the stained cell score with the staining intensity score. The final score ranged from 0 to 9 . Low expression was defined as a final score of $<4$ and high expression a score of $\geq 4$.

Count of MVD in colorectal cancer. EnVision staining was used. Vascular endothelial cells were labeled with CD34, and brown cytoplasmic staining was considered positive. MVD standard reference Weidner [12] method: a single endothelial cell, an endothelial cell cluster, and a vessel with a lumen and containing 1-2 smooth muscles were counted as microvessels. The microvascular distribution of the area with the highest density was selected at low magnification $(\times 40)$, and the number of microvessels was counted at magnification $(\times 200)$. Their average is the MVD value of the sample.

Western blotting analysis. Tissue samples were homogenized in SDS buffer containing the protease inhibitor PMSF. The homogenates were incubated on ice for $20 \mathrm{~min}$ and then centrifuged at $13500 \times \mathrm{g}$ for $30 \mathrm{~min}$ at $4{ }^{\circ} \mathrm{C}$. The supernatant was collected and mixed with a similar volume of $2 \times$ SDS buffer. The mixture was boiled for $10 \mathrm{~min}$ and preserved at $-20^{\circ} \mathrm{C}$. The protein extracts $(50 \mu \mathrm{g})$ were separated using SDS-PAGE and then transferred onto polyvinylidene difluoride membrane (Millipore, USA). The membranes were blocked with $5 \%$ nonfat milk in Tris-buffered saline containing $0.1 \%$ Tween-20 at room temperature for 90 min. The membranes were then immunoblotted for Raptor (1:1000; Abcam), Rictor (1:1000; Abcam), HIF-1a (1:500; Abcam), HIF-2a (1:1000; Abcam), VEGF (1:500; Abcam), and $\beta$-actin (1:1000; Abcam). Proteins bands were detected with secondary antibodies conjugated to horseradish peroxidase (1:5000, Abcam) and visualized with enhanced chemiluminescence reagents. Each band was quantified through densitometry, and results were presented as the relative expression of each protein from different samples.

Real-time PCR analysis. Total RNA was extracted from fresh-frozen tumor specimens and the corresponding noncancerous tissues by using Trizol reagent (Invitrogen, China). The amount of RNA was determined with the absorbance at $260 \mathrm{~nm}$, and its purity was estimated using the ratio of the absorbance at A260/280. The total RNA was reverse transcribed using PrimeScript RT reagent kit (Takara, DRR037A, China). ). The RT-PCR was carried on CFX96T RT-PCR Detection System C1000 (Applied Biosystems, China) using the following conditions: the first denaturation step at $95^{\circ} \mathrm{C}$ for $30 \mathrm{~s}$, followed by 40 cycles at $95^{\circ} \mathrm{C}$ for $5 \mathrm{~s}$ and $60^{\circ} \mathrm{C}$ for $30 \mathrm{~s}$. For each sample, a relative quantity was calculated using the $2^{-\Delta \Delta C(T)}$ method. For SYBR GREEN I-based real-time PCR reactions, each $25 \mu \mathrm{l}$ of the reaction mixture contained $2 \mu \mathrm{l}$ of primer pairs, $2 \mu \mathrm{l}$ of cDNA, $12.5 \mu \mathrm{l}$ of SYBR Premix Ex Taq II, and ddH2O in a final volume of $25 \mu \mathrm{l}$. Nucleotide sequences of specific primers for the selected genes were as follows: Raptor forward primer 5'-TCCCACCAG-AAGAAGGTTCC-3' and reverse primer 
5'-GGGACTCTCTACACCTTCCG-3'; Rictor forward primer 5'-TTTACACTGCTTGCCAACCC-3' and reverse primer 5'-ACTGATCCCGTTTCTGGTGT-3'; Hif-1a forward primer 5'-TCCAAGAAGCCCTAACGTGT-3' and reverse primer 5'-ATGATCGTCTGGCTGCTGTA-3'; Hif-2a forward primer 5'-CAACCTGCAGCCTCAGTGTATC-3' and reverse primer 5'-ACCACGTCGTTCTTCTCGAT-3'; VEGF forward primer 5'-GGCCAGCACATAGGAGAGAT-3' and reverse primer 5'-ACACGTCTGCGGATCTTGTA-3'.

Statistical analysis. All statistical analyses were conducted with the SPSS 20.0 software (SPSS, Chicago, USA). The results of MVD were expressed as mean \pm SD. Fisher's exact test or chi-square test was used to analyze data from independent groups. Multiple linear regression analysis was used to analyze the relationship between Raptor, Rictor, HIF-1 $\alpha$, HIF-2 $\alpha$, VEGF and the factors of clinical pathology. Statistical significance was considered at $\mathrm{p}<0.05$.

\section{Results}

Expression of Raptor, Rictor, HIF-1 $\alpha$, HIF-2 $\alpha$ and VEGF. To explore the expression of Raptor, Rictor, HIF-1 $\alpha$, HIF- $2 \alpha$ and VEGF, we used immunohistochemistry, western blot analysis and real-time PCR in human CRC and matched adjacent non-tumor tissues. The immunohistochemical results are shown in Figure 1. The expression levels of Raptor, Rictor, LC3, HIF-1 $\alpha$, HIF- $2 \alpha$ and VEGF were positive in the cytoplasm or nuclei in CRC samples. The positive ratios were $52.50 \%, 60 \%, 69.17 \%, 48.33 \%$ and $74.17 \%$. In addition, western blot analysis and real-time PCR results showed that Raptor, Rictor, LC3, HIF- $1 \alpha$, HIF-2 $\alpha$ and VEGF expressions were significantly higher in the CRC samples than in the non-tumor tissues $(\mathrm{p}<0.05)$ (Figure 2$)$.
Correlation of clinical parameters according to Raptor, Rictor HIF-1 $\alpha$, HIF- $2 \alpha$ and VEGF status. We analyzed the correlation between the Raptor, Rictor, HIF- $1 \alpha$, HIF- $2 \alpha$ and VEGF expression levels of CRC samples and a set of clinicopathological parameters, including age, sex, histologic type and tumor site (Table 1). In moderately and poorly differentiated CRC, Raptor $(66.67 \%$ and $78.95 \%$, respectively) and Rictor ( $81.48 \%$ and $84.21 \%$, respectively) expressions were higher than in well-differentiated CRC (Raptor: 40.54\%; Rictor: 45.95\%). The expression levels of Raptor, Rictor, HIF- $1 \alpha$, HIF- $2 \alpha$ and VEGF in the presence of lymph node metastasis $(72.73 \%, 75.76 \%, 84.85 \%, 72.73 \%$ and $87.88 \%$, respectively) are higher than without $(44.83 \%, 54.02 \%$, $63.22 \%, 39.08 \%$ and $68.97 \%$, respectively).

Correlation of Raptor and Rictor with MVD in CRC tissues. The CD34-labeled tumor microvessels were counted by immunohistochemistry. The number of CD34-positive microvessels was between $25.24 \pm 6.34$ and $41.32 \pm 9.56$ in CRC. The MVD was higher in patients with positive Raptor or Rictor $(41.32 \pm 9.56,3.47 \pm 7.38)$ than those without $(29.73 \pm 6.63,5.24 \pm 6.34)$. As shown in Table 2, Raptor and Rictor expression is positively correlated with those of MVD ( $r s=0.432, \mathrm{p}<0.05 ; \mathrm{rs}=0.313, \mathrm{p}<0.05)$. Thus, increased Raptor and Rictor expression lead to elevated MVD.

Correlation of Raptor and Rictor and HIF- $1 \alpha$, HIF- 2 and VEGF in CRC tissues. As shown in Table 2, Raptor expression is positively correlated with HIF- $1 \alpha\left(r_{s}=0.557, p<0.05\right)$ and not with HIF- $2 \alpha\left(r_{s}=0.085, p>0.05\right)$. Rictor expression is positively correlated with HIF- $2 \alpha\left(\mathrm{r}_{\mathrm{s}}=0.551, \mathrm{p}<0.05\right)$ and not with HIF-1 $\alpha\left(r_{s}=-0.177, p>0.05\right)$. Raptor and Rictor expression is positively correlated with VEGF $\left(r_{s}=0.233, p<0.05\right.$; $\left.r_{s}=0.248, p<0.05\right)$. Raptor expression is negatively correlated with Rictor $\left(r_{s}=-0.402, p<0.05\right)$.
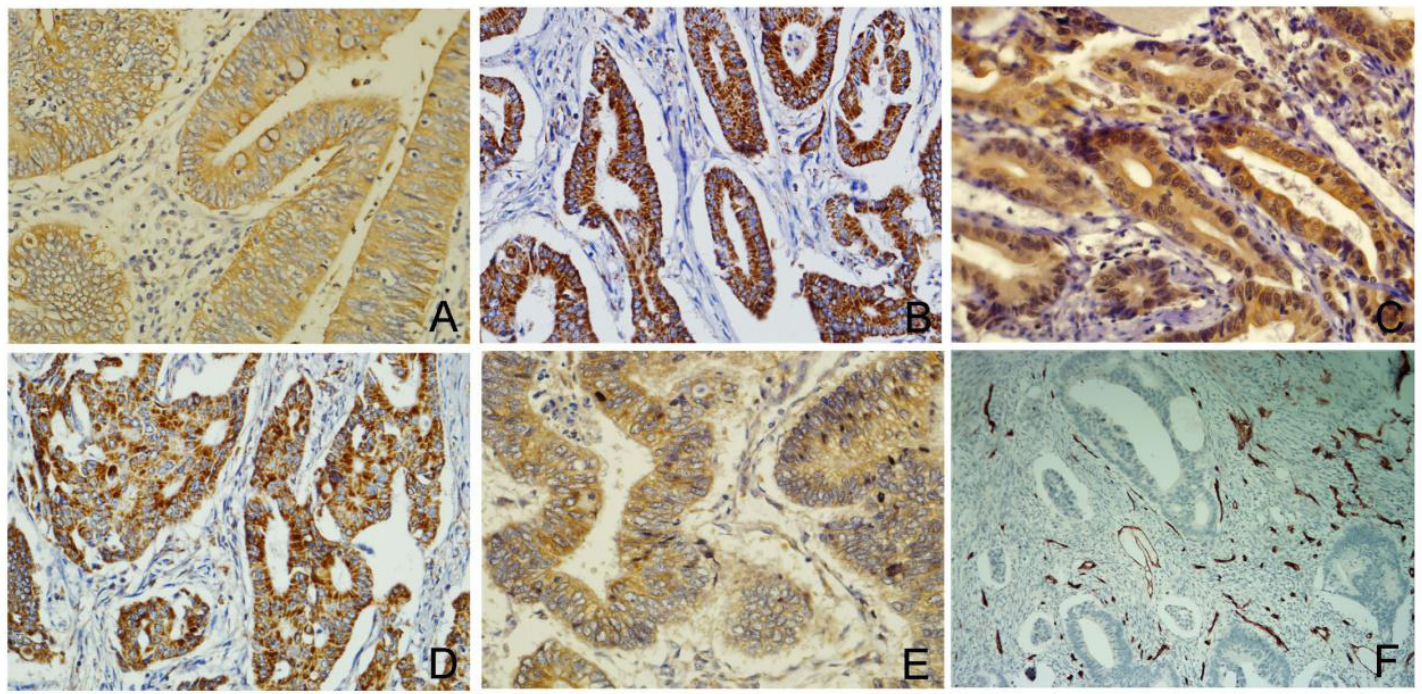

Figure 1. Immunohistochemical staining of Raptor, Rictor, HIF-1 $\alpha$, HIF-2a, VEGF and CD34 protein expressions in CRC tissues. High-power view (original magnification $\times 200$ ) shows strong staining for Raptor, Rictor, HIF-2 $\alpha$ and VEGF in the cytoplasm of cancer cells (Raptor (A); Rictor (B); HIF-2 $\alpha$ (D); VEGF (E)), HIF-1 $\alpha$ in the cytoplasm and nucleus of cancer cells (C), vascular endothelial cells were labeled with CD34 (F). 
Table 1. Relation between Raptor, Rictor, HIF-1 $\alpha$, HIF-2 $\alpha$, VEGF and clinicopathological parameters for CRC.

\begin{tabular}{|c|c|c|c|c|c|c|c|c|c|c|c|}
\hline Variable & $\mathrm{N}$ & $\begin{array}{c}\text { Raptor } \\
(+)\end{array}$ & $\mathrm{p}$-value & $\begin{array}{c}\text { Rictor } \\
(+)\end{array}$ & $\mathrm{p}$-value & $\begin{array}{c}\text { HIF-1a } \\
(+)\end{array}$ & $\mathrm{p}$-value & $\begin{array}{c}\text { HIF- } 2 \alpha \\
(+)\end{array}$ & $\mathrm{p}$-value & $\begin{array}{c}\text { VEGF } \\
(+)\end{array}$ & $\mathrm{p}$-value \\
\hline \multicolumn{12}{|l|}{ Age } \\
\hline$<60$ & 65 & 33 & 0.680 & 38 & 0.708 & 47 & 0.418 & 31 & 0.879 & 48 & 0.931 \\
\hline$\geq 60$ & 55 & 30 & & 34 & & 36 & & 27 & & 41 & \\
\hline \multicolumn{12}{|l|}{ Sex } \\
\hline Male & 63 & 34 & 0.735 & 39 & 0.654 & 43 & 0.820 & 30 & 0.869 & 47 & 0.909 \\
\hline Female & 57 & 29 & & 33 & & 40 & & 28 & & 42 & \\
\hline \multicolumn{12}{|l|}{ Tumor sizes $(\mathrm{cm})$} \\
\hline$<5$ & 68 & 35 & 0.796 & 39 & 0.498 & 46 & 0.680 & 31 & 0.491 & 49 & 0.546 \\
\hline$\geq 5$ & 52 & 28 & & 33 & & 37 & & 27 & & 40 & \\
\hline \multicolumn{12}{|l|}{ Tumor site } \\
\hline Colon & 49 & 27 & 0.635 & 28 & 0.596 & 34 & 0.965 & 24 & 0.906 & 35 & 0.569 \\
\hline Rectal & 71 & 36 & & 44 & & 49 & & 34 & & 54 & \\
\hline \multicolumn{12}{|l|}{ Differentiation degree } \\
\hline High & 74 & 30 & $0.003^{\star}$ & 34 & $0.000^{*}$ & 49 & 0.536 & 35 & 0.917 & 55 & 0.784 \\
\hline Moderate & 27 & 18 & & 22 & & 21 & & 13 & & 19 & \\
\hline Low & 19 & 15 & & 16 & & 13 & & 10 & & 15 & \\
\hline \multicolumn{12}{|l|}{ Depth of invasion } \\
\hline Mucosa and submucosa & 17 & 8 & 0.859 & 7 & 0.195 & 11 & 0.341 & 8 & 0.440 & 10 & 0.159 \\
\hline Muscularis propria & 33 & 17 & & 18 & & 20 & & 17 & & 23 & \\
\hline Serous & 70 & 38 & & 45 & & 52 & & 43 & & 56 & \\
\hline \multicolumn{12}{|l|}{ Lymph node metastasis } \\
\hline No & 87 & 39 & $0.006^{*}$ & 47 & $0.030^{*}$ & 55 & $0.022^{*}$ & 34 & $0.001^{*}$ & 60 & $0.035^{\star}$ \\
\hline Yes & 33 & 24 & & 25 & & 28 & & 24 & & 29 & \\
\hline
\end{tabular}

*indicate statistically significant $(\mathrm{p}<0.05)$
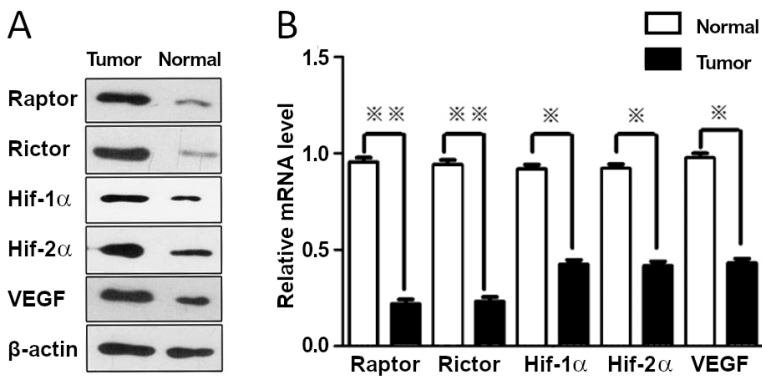

Figure 2. Western blotting and real-time-PCR analysis showed that the protein expressions of Raptor, Rictor, HIF-1 $\alpha$, HIF- $\alpha$ and VEGF in human CRC tissues in comparison with non-tumor tissues have more upregulated expression.

Correlation between Raptor, Rictor, HIF-1 $\alpha$, HIF-2 $\alpha$ and VEGF expression levels and patient OS. The median survival time of 120 cases patients was 60 months, and the five-year survival rate of patients was $45.8 \%$. Kaplan-Meier analysis (Figure 3) revealed that Raptor, Rictor, HIF-1a, HIF-2 $\alpha$ and VEGF expression and lymph node metastasis could be relevant predictive factors of OS. The 5-year survival rate of patients with positive and negative expression of Raptor was $28.6 \%$ and $47.4 \%$, respectively $(\mathrm{p}<0.01$, Figure $3 \mathrm{~A}$ ). The 5 -year survival rate of patients with positive and negative expression of Rictor was $38.9 \%$ and $56.3 \%$, respectively $(\mathrm{p}<0.05$, Figure $3 \mathrm{~B})$. The 5 -year survival rate of patients with positive and negative expression of HIF-1a was $38.6 \%$ and $62.2 \%$, respectively ( $p<0.01$, Figure $3 C)$. The 5 -year survival rate of patients with positive and negative expression of HIF-2 $\alpha$ was $31.0 \%$ and $59.7 \%$, respectively $(\mathrm{p}<0.05$, Figure $3 \mathrm{D})$. The 5 -year survival rate of patients with positive and negative expression of VEGF was $38.2 \%$ and $67.7 \%$, respectively ( $\mathrm{p}<0.01$, Figure $3 \mathrm{E}$ ). Cox regression analysis showed that Raptor, Rictor, HIF-2 $\alpha$ and VEGF expression and lymph node metastasis were independent prognostic factors of CRC (Table 3).

\section{Discussion}

CRC is common cancer of the digestive system in China. At present, surgery is the main treatment, combined with chemotherapy. Targeted therapy has become the new development direction of CRC's clinical treatment because of its significant treatment effect. However, why antiangiogenic therapy is ineffective for CRC is not yet clear. Therefore, a study of CRC angiogenesis mechanisms has important significance to provide a theoretical basis for more effective treatment. Sun [13] confirmed that activation of mTORC1 can upregulate HIF-1a expression in angiogenic sarcoma cells, thereby increasing angiogenesis. Studies have shown that inhibition of gastric cancer cell mTORC1 expression can downregulate the level of HIF-1a and reduce gastric cancer cell angiogenesis [14]. Ilhan [15] have confirmed that 
mTORC2 regulates HIF-2 $\alpha$ expression and then regulates its angiogenesis in neuroblastoma. Therefore, we speculate that mTOR may regulate CRC angiogenesis in a variety of ways.

mTOR has two subtypes: mTORC1 and mTORC2, which, respectively, contain the Raptor and Rictor core molecules [16-17]. The expression level of Raptor and Rictor can reflect the biological activity of mTORC1 and mTORC2, and its specificity and sensitivity are higher than that of compound molecules. In this study, the expressions of Raptor, Rictor, HIF-1 $\alpha$, HIF- $2 \alpha$ and VEGF in CRC were investigated. Their positive rates were $52.50 \%, 60 \%, 69.17 \%$, $48.33 \%$, and $74.17 \%$ in CRC samples, and significantly lower in matched non-tumor tissues: $20 \%, 25 \%, 23.33 \%, 18.33 \%$, and $28.33 \%$. Clinicopathological parameter analysis showed that the expressions of Raptor and Rictor were associated with the degree of differentiation and lymph node metastasis $(\mathrm{p}<0.05)$. Moreover, previous studies have also shown that mTOR, Raptor, and Rictor protein levels were also significantly elevated in primary CRCs (stage IV) and their matched distant metastases compared with a normal colon [18]. In addition, the MVD was higher in patients with positive Raptor or Rictor than those without, suggesting that Raptor and Rictor are not only associated with tumor angiogenesis, and the occurrence and development, invasion, metastasis and prognosis of CRC.

HIF family members HIF- $1 \alpha$ and HIF- $2 \alpha$ are important target genes downstream of the PI3K/AKT/mTOR signaling pathway $[10,19]$. They are important factors in the regulation of cellular responses in hypoxic conditions. HIF-1 $\alpha$ and HIF- $2 a$ can effectively activate VEGF expression and promote angiogenesis. Therefore, they are conducive to alleviate local tissue hypoxia. In this study, Raptor, Rictor, HIF-1 $\alpha$, HIF- $2 \alpha$ and VEGF were detected in CRC, and their correlation was analyzed. Results show that Raptor and Rictor expression is positively correlated with those of VEGF. However, Raptor expression is positively correlated with HIF- $1 \alpha$, whereas Rictor is positively correlated with HIF-2a. This finding suggests that Raptor and Rictor are involved in the regulation of tumor angiogenesis through different pathways. mTORC1 plays a role in promoting tumor vascular endothelial cell proliferation in a variety of tumors [20,21]. Alternatively, mTORC2 can regulate endothelial cell skeleton changes and vascular endothelial migration and promote tumor angiogenesis [22]. Pat Gulhati et al. reported RhoA and Rac1 pathways as a critical downstream mechanism by which
mTORC1 and mTORC2 may regulate changes in the actin cytoskeleton and cell migration [18]. We believe that in CRC, Raptor can increase HIF-1 $\alpha$ and VEGF expression, thereby promoting the growth and proliferation of vascular endothelial cells and that Rictor can upregulate HIF-2 $\alpha$ expression, which is involved in the reconstruction of the cytoskeleton, endothelial cell proliferation, migration and upregulation of VEGF, ultimately promoting angiogenesis.
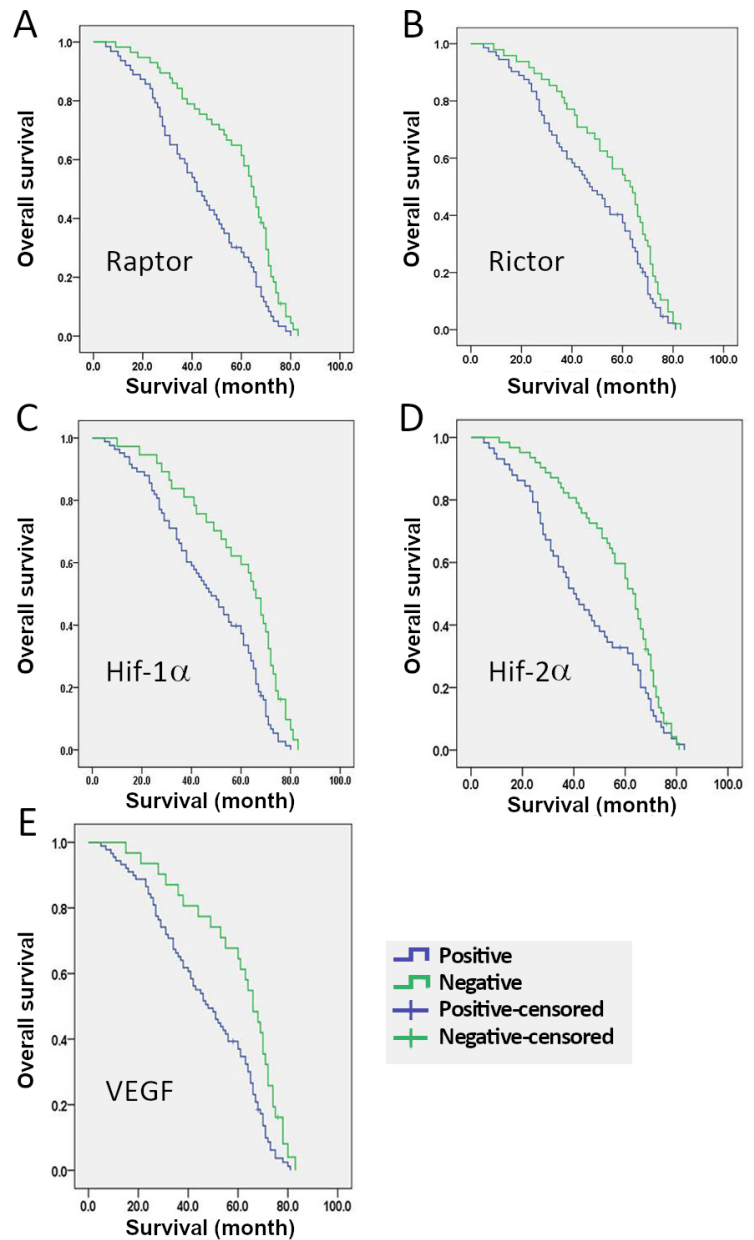

Figure 3. Kaplan-Meier survival curves for Raptor (A), Rictor (B), HIF$1 \alpha(C)$, HIF-2 $\alpha$ (D) and VEGF (E) expression in CRC. In Kaplan-Meier analysis, high Raptor, Rictor, HIF-1 $\alpha$, HIF- $2 \alpha$ and VEGF expressions correlated with a shorter OS in CRC patients than the corresponding controls.

Table 2. Correlation of Raptor, Rictor with HIF-1 $\alpha$, HIF-2 $\alpha$, VEGF and MVD in CRC.

\begin{tabular}{|c|c|c|c|c|c|c|c|c|c|c|c|c|c|}
\hline & & \multirow{2}{*}{$\mathrm{N}$} & \multicolumn{2}{|c|}{ HIF-1a } & \multirow{2}{*}{$\mathrm{p}$-value } & \multicolumn{2}{|c|}{ HIF-2a } & \multirow{2}{*}{$\mathrm{p}$-value } & \multicolumn{2}{|c|}{ VEGF } & \multirow{2}{*}{ p-value } & \multirow{2}{*}{ MVD } & \multirow{2}{*}{ p-value } \\
\hline & & & - & + & & - & + & & - & + & & & \\
\hline \multirow{2}{*}{ Raptor } & - & 57 & 33 & 24 & \multirow{2}{*}{$0.000^{\star}$} & 32 & 25 & \multirow{2}{*}{0.351} & 21 & 36 & \multirow{2}{*}{$0.012^{\star}$} & $29.73 \pm 6.63$ & \multirow{2}{*}{$0.021^{\star}$} \\
\hline & + & 63 & 4 & 59 & & 30 & 33 & & 10 & 53 & & $41.32 \pm 9.56$ & \\
\hline \multirow{2}{*}{ Rictor } & - & 48 & 10 & 38 & \multirow{2}{*}{0.053} & 41 & 7 & \multirow{2}{*}{$0.000^{*}$} & 19 & 29 & \multirow{2}{*}{$0.006^{\star}$} & $25.24 \pm 6.34$ & \multirow{2}{*}{$0.016^{\star}$} \\
\hline & + & 72 & 27 & 45 & & 21 & 51 & & 12 & 60 & & $33.47 \pm 7.38$ & \\
\hline
\end{tabular}

*indicate statistically significant $(\mathrm{p}<0.05)$ 
Table 3. Univariate and multivariate analysis of clinicopathologic parameters with OS by Cox proportional hazards regression.

\begin{tabular}{|c|c|c|c|c|c|c|c|}
\hline \multirow{2}{*}{$\begin{array}{l}\text { Variable } \\
\text { Age }(<60, \geq 60)\end{array}$} & \multirow{2}{*}{$\begin{array}{c}\text { B } \\
0.047\end{array}$} & \multirow{2}{*}{$\begin{array}{c}\text { SE } \\
0.208\end{array}$} & \multirow{2}{*}{$\begin{array}{c}\text { Wald } \\
0.050\end{array}$} & \multirow{2}{*}{$\begin{array}{c}\text { p-value } \\
0.823\end{array}$} & \multirow{2}{*}{$\frac{\operatorname{Exp}(\mathbf{B})}{1.048}$} & \multicolumn{2}{|c|}{$\begin{array}{l}\text { RFS hazard ratio } \\
(95 \% \mathrm{Cl})\end{array}$} \\
\hline & & & & & & 0.697 & 1.575 \\
\hline Gender (male, female) & -0.042 & 0.211 & 0.040 & 0.841 & 0.959 & 0.634 & 1.449 \\
\hline Tumor sizes $(<5, \geq 5)$ & 0.075 & 0.218 & 0.118 & 0.731 & 1.078 & 0.703 & 1.654 \\
\hline Tumor site (colon, rectal) & -0.212 & 0.206 & 1.051 & 0.305 & 0.809 & 0.540 & 1.213 \\
\hline Histologic grade (Grade 1, Grade 2, Grade 3) & -0.312 & 0.281 & 1.296 & 0.523 & 0.732 & 0.422 & 1.269 \\
\hline $\begin{array}{l}\text { Depth of invasion } \\
\text { (Mucosa and submucosa, Myometrium, Epicardial) }\end{array}$ & 0.519 & 0.323 & 4.975 & 0.083 & 0.834 & 0.534 & 1.302 \\
\hline Lymph node metastasis (yes, no) & -0.623 & 0.244 & 6.545 & $0.011^{*}$ & 0.536 & 0.333 & 0.864 \\
\hline Rictor & 0.538 & 0.239 & 5.065 & $0.024^{*}$ & 1.712 & 1.072 & 2.734 \\
\hline HIF1a & 0.429 & 0.231 & 3.456 & 0.063 & 1.536 & 0.977 & 2.416 \\
\hline HIF $2 a$ & 0.675 & 0.204 & 10.979 & $0.001^{*}$ & 1.963 & 1.317 & 2.926 \\
\hline VEGF & 0.588 & 0.237 & 6.180 & $0.013^{*}$ & 1.801 & 1.133 & 2.864 \\
\hline Raptor & -0.505 & 0.222 & 5.161 & $0.023^{*}$ & 0.604 & 0.390 & 0.933 \\
\hline
\end{tabular}

*indicate statistically significant $(\mathrm{p}<0.05)$

Studies have shown that various factors affect tumor angiogenesis, most especially, the tuberculous capillary endothelial cell buds and VEGF [23-26]. This study showed that in CRC, VEGF was highly expressed; its expression was positively correlated with Raptor, Rictor and tumor MVD; and Raptor expression was negatively correlated with Rictor. Recent studies have shown that the function and role of Raptor and Rictor are different in the PI3K/AKT/mTOR signaling pathway and a negative feedback loop exists between them [27]. Akt, the most well-characterized mTORC2 target, is able to phosphorylate S939/981 of tuberin (TSC2), the upstream suppressor of mTORC1, consequently leading to mTORC1 activation. Additionally, mTORC1, its substrate p70 ribosomal S6 kinase 1 (S6K1), inhibits mTORC2-Akt signaling by Rictor phosphorylation at T1135 [28]. A study has shown that Rictor inhibition led to impaired secretion of vascular-endothelial growth factor-A (VEGF-A) and diminished expression of hypoxia-induced factor-1a (HIF-1a) [29]. Therefore, we believe that in the process of tumor ischemia and hypoxia to start angiogenesis, Raptor and Rictor both coordinate with each other and regulates each other. High expression of Raptor can promote angiogenesis. However, when it is inhibited, it can activate Rictor, which then upregulates HIF-2a expression and promote angiogenesis, alleviating hypoxia. At the same time, Rictor through the negative feedback loop can re-activate Raptor, which then upregulates HIF-1 $\alpha$ and VEGF expression, promoting angiogenesis. The results suggest that Raptor and Rictor are the core molecules of $\mathrm{mTOR}$ in the $\mathrm{PI} 3 \mathrm{~K} / \mathrm{AKT} / \mathrm{mTOR}$ signaling pathway, both of which regulate each other in tumor angiogenesis and promote angiogenesis of CRC. Exploring the different functions of Raptor and Rictor as new target blockers can become a new idea for the development of tumor angiogenesis blockers.
In this study, we followed up 120 cases of CRC patients and found that the prognosis of CRC was not only correlated with the clinical and pathological factors, such as lymph node metastasis. In addition, the protein expression levels of Raptor, Rictor, HIF- $1 \alpha$, HIF- $2 \alpha$ and VEGF are closely related to the prognosis of patients with $\mathrm{CRC}$. Cox regression analysis showed that Raptor, Rictor, HIF-2 $\alpha$ and VEGF expression and lymph node metastasis were independent prognostic factors of CRC. All these results suggest that Raptor, Rictor, HIF-1 $\alpha$, HIF-2 $\alpha$ and VEGF expression can be important factors in analyzing the prognosis of CRC. Combining these expressions with the traditional clinicopathological factors can improve prognosis accuracy for patients with CRC.

In conclusion, Raptor and Rictor expressions are increased in CRC and correlated to HIF- $1 \alpha$, HIF- $2 \alpha$ and VEGF. Raptor and Rictor are important genes for the regulation of angiogenesis in CRC and are associated with clinicopathological factors such as CRC differentiation and lymph node metastasis. Therefore, the combined detection of Raptor and Rictor expression in CRC helps to assess the progression of the disease and the choice of the treatment regimen, which is of great value in improving the clinical efficacy of anti-tumor vascular drugs.

Acknowledgments: This work was supported by the National natural science foundation, China (No: 50012301142).

\section{References}

[1] NAUMOV G, AKSLEN L, FOLKMAN J. Role of angiogenesis in human tumor dormancy: animal models of the angiogenic switch. Cell Cycle 2006; 5: 1779-1787. https://doi. org/10.4161/cc.5.16.3018 
[2] SIVEEN K, PRABHU K, KRISHNANKUTTY R, KUTTIKRISHNAN S, TSAKOU $M$ et al. Vascular Endothelial Growth Factor (VEGF) Signaling in Tumour Vascularization: Potential and Challenges. Curr Vasc Pharmacol 2017; 15: 339-351. https://doi.org/10.2174/1570161115666170105 124038

[3] SHIBUTANI M, MAEDA K, NAGAHARA H, FUKUOKA T, LSEKI Y et al. Two Cases of Long-Term Control of Metastatic Colorectal Cancer via FTD/TPI plus Bevacizumab in Elderly Patients. Case Rep Oncol 2018; 11: 800-805. https:// doi.org/10.1159/000493849

[4] AMIN A, PLIMACK E, ERNSTOFF M, LEWIS L, BAUER T et al. Safety and efficacy of nivolumab in combination with sunitinib or pazopanib in advanced or metastatic renal cell carcinoma: the CheckMate 016 study. J Immunother Cancer 2018; 6: 109. https://doi.org/10.1186/s40425-018-0420-0

[5] ABDELGAliL A, ALKAHTANI H, Al-JENOOBI F. Sorafenib. Profiles Drug Subst Excip Relat Methodol 2019; 44: 239-266. https://doi.org/10.1016/bs.podrm.2018.11.003

[6] RAMJIAWAN R, GRIFFIOEN A, DUDA D. Anti-angiogenesis for cancer revisited: Is there a role for combinations with immunotherapy? Angiogenesis 2017; 20: 185-204. https:// doi.org/10.1007/s10456-017-9552-y

[7] LI J, MAO X, TIAN T, WANG W, SU T et al. Role of PFKFB3 and CD163 in Oral Squamous Cell Carcinoma Angiogenesis. Curr Med Sci 2019; 39: 410-414. https://doi.org/10.1007/ s11596-019-2051-1

[8] ZENG Z, GAO ZL, ZHANG ZP, JIANG HB, YANG CQ et al. Downregulation of CKS1B restrains the proliferation, migration, invasion and angiogenesis of retinoblastoma cells through the MEK/ERK signaling pathway. Int J Mol Med 2019; 44: 103-114. https://doi.org/10.3892/ijmm.2019.4183

[9] CHEN M, LU J, WEI W, LV Y, ZHANG X et al. Effects of proton pump inhibitors on reversing multidrug resistance via downregulating V-ATPases/PI3K/Akt/mTOR/HIF-1a signaling pathway through TSC1/2 complex and Rheb in human gastric adenocarcinoma cells in vitro and in vivo. Onco Targets Ther 2018; 11: 6705-6722. https://doi.org/10.2147/ OTT.S161198

[10] MI C, MA J, SHI H, LI J, WANG F et al. 4', 6-dihydroxy4-methoxyisoaurone inhibits the HIF-1a pathway through inhibition of Akt/mTOR/p70S6K/4E-BP1 phosphorylation. J Pharmacol Sci 2014; 125: 193-201. https://doi.org/10.1254/ jphs.13273fp

[11] WANG S, AMATO KR, SONG W, YOUNGBLOOD V, LEE $\mathrm{K}$ et al. Regulation of endothelial cell proliferation and vascular assembly through distinct mTORC2 signaling pathways. Mol Cell Biol 2015; 35: 1299-1313. https://doi.org/10.1128/ MCB.00306-14

[12] WEIDNER N, SEMPLE JP, WELCH WR, FOLKMAN J. Tumor angiogenesis and metastasis correlation in invasive breast carcinoma. N Engl J Med 1991; 324: 1-8. https://doi. org/10.1056/NEJM199101033240101

[13] SUN S, CHEN S, LIU F, WU H, MCHUGH J et al. Constitutive Activation of mTORC1 in Endothelial Cells Leads to the Development and Progression of Lymphangiosarcoma through VEGF Autocrine Signaling. Cancer Cell 2015; 28: 758-772. https://doi.org/10.1016/j.ccell.2015.10.004
[14] CEJKA D, PREUSSER M, WOEHRER A, SIEGHART W, STROMMER S et al. Everolimus (RAD001) and anti-angiogenic cyclophosphamide show long-term control of gastric cancer growth in vivo. Cancer Biol Ther 2008; 7: 1377-1385. https://doi.org/10.4161/cbt.7.9.6416

[15] MOHLIN S, HAMIDIAN A, VON STEDINGK K, BRIDGES E, WIGERUP C et al. PI3K-mTORC2 but not PI3K-mTORC1 regulates transcription of HIF2A/EPAS1 and vascularization in neuroblastoma. Cancer Res 2015; 75: 4617-4628. https:// doi.org/10.1158/0008-5472.CAN-15-0708

[16] LIANG X, DENG M, ZHANG C, PING F, WANG $\mathrm{H}$ et al. Combined class I histone deacetylase and mTORC1/C2 inhibition suppresses the initiation and recurrence of oral squamous cell carcinomas by repressing SOX2. Cancer Lett 2019; 454: 108-119. https://doi.org/10.1016/j.canlet.2019.04.010

[17] ALLEN SA, TOMILOV A, CORTOPASSI GA. Small molecules bind human mTOR protein and inhibit mTORC1 specifically. Biochem Pharmacol 2018; 155: 298-304. https:// doi.org/10.1016/j.bcp.2018.07.013

[18] GULHATI P, BOWEN KA, LIU J, STEVENS PD, RYCHAHOU PG et al. mTORC1 and mTORC2 regulate EMT, motility, and metastasis of colorectal cancer via RhoA and Rac1 signaling pathways. Cancer Res 2011; 71: 3246-3256. https:// doi.org/10.1158/0008-5472.CAN-10-4058

[19] HUANG Y, LIN D, Taniguchi CM. Hypoxia inducible factor (HIF) in the tumor microenvironment: friend or foe? Sci China Life Sci 2017; 60: 1114-1124. https://doi.org/10.1007/ s11427-017-9178-y

[20] REHO JJ, GUO DF, RAHMOUNI K. Mechanistic Target of Rapamycin Complex 1 Signaling Modulates Vascular Endothelial Function Through Reactive Oxygen Species. J Am Heart Assoc 2019; 8: e010662. https://doi.org/10.1161/ JAHA.118.010662

[21] TSUJI-TAMURA K, OGAWA M. Inhibition of the PI3K/Akt and mTORC1 signaling pathways promotes the elongation of vascular endothelial cell. J Cell Sci 2016; 129: 1165-1178. https://doi.org/10.1242/jcs.178434

[22] LAMANUZZI A, SALTARELLA I, DESANTIS V, FRASSANITO MA, LEONE P et al. Inhibition of mTOR complex 2 restrains tumor angiogenesis in multiple myeloma. Oncotarget 2018; 9: 20563-20577. https://doi.org/10.18632/oncotarget. 25003

[23] DAVIES EM, GURUNG R, LE KQ, MITCHELL CA. Effective angiogenesis requires regulation of phosphoinositide signaling. Adv Biol Regul 2019; 71: 69-78. https://doi. org/10.1016/j.jbior.2018.11.008

[24] SEOK J, YOON SH, LEE SH, JUNG JH, LEE YM. The oncometabolite d-2-hydroxyglutarate induces angiogenic activity through the vascular endothelial growth factor receptor 2 signaling pathway. Int J Oncol 2019; 54: 753-763. https://doi. org/10.3892/ijo.2018.4649

[25] LIN J, CAO S, WANG Y, HU Y, LIU H et al. Long non-coding RNA UBE2CP3 enhances HCC cell secretion of VEGFA and promotes angiogenesis by activating ERK1/2/HIF-1a/ VEGFA signalling in hepatocellular carcinoma. J Exp Clin Cancer Res 2018; 37: 113. https://doi.org/10.1186/s13046018-0727-1 
[26] MELINCOVICI CS, BOŞCA AB, ŞUŞMAN S, MĂRGINEAN M, MIHU C et al. Vascular endothelial growth factor (VEGF) - key factor in normal and pathological angiogenesis. Rom J Morphol Embryol 2018; 59: 455467.

[27] SHUHUA W, CHENBO S, YANGANG L, XIANGQIAN G SHUANG $\mathrm{H}$ et al. Autophagy-related genes Raptor, Rictor, and Beclin1 expression and relationship with multidrug resistance in colorectal carcinoma. Hum Pathol 2015; 46: 1752-1759. https://doi.org/10.1016/j.humpath.2015.07.016
[28] ZOU Z, CHEN J, YANG J, BAI X. Targeted Inhibition of Rictor/mTORC2 in Cancer Treatment: A New Era after Rapamycin. Curr Cancer Drug Targets 2016; 16: 288-304. https:// doi.org/10.2174/1568009616666151113120830

[29] SCHMIDT KM, HELLERBRAND C, RUEMMELE P, MICHALSKI CW, KONG B et al. Inhibition of mTORC2 component RICTOR impairs tumor growth in pancreatic cancer models. Oncotarget 2017; 8: 24491-24505. https://doi. org/10.18632/oncotarget.15524 